\title{
Properties of nitrogen-implanted beryllium and its interaction with energetic deuterium
}

\author{
M. Oberkofler and Ch. Linsmeier \\ Max-Planck-Institut für Plasmaphysik, EURATOM Association, Boltzmannstraße 2, \\ 85748 Garching b. München, Germany \\ E-mail: linsmeier@ipp.mpg.de
}




\begin{abstract}
.
Recent successful experiments with nitrogen as a seeding gas in fusion plasma devices, together with the decision to use beryllium as an armor material in the international fusion experiment ITER, have triggered the interest in interactions of energetic $\mathrm{N}$ ions with Be and the influence of possible compound formation on parameters relevant to reactor operation and safety. Laboratory experiments are performed to investigate the properties of the 'mixed material' formed upon bombardment of bulk Be with energetic (keV) nitrogen ions. The formation of beryllium nitride within the implantation zone of a few $\mathrm{nm}$ is observed by $\mathrm{X}$ ray photoelectron spectroscopy and Rutherford backscattering spectrometry. Upon implantation of $\mathrm{N}$ at $1.5 \mathrm{keV}$ per atom, saturation of the Be surface with $\mathrm{N}$ occurs at a fluence of $2 \times 10^{18} \mathrm{~N} \mathrm{~cm}^{-2}$ and a retained areal density of approx. $4 \times 10^{16} \mathrm{~N} \mathrm{~cm}^{-2}$. The nitride undergoes an ordering process upon annealing, but does not decompose at temperatures up to $1000 \mathrm{~K}$. The influence of such nitride layers on the retention and the release of D implanted with different fluences is investigated by nuclear reaction analysis and temperature-programmed desorption. The nitride layer does not act as a diffusion barrier for out-diffusing hydrogen isotopes. A partial sputter yield of 0.013 $\mathrm{N} / \mathrm{D}$ as a lower limit is measured upon bombardment of the nitride layer with $\mathrm{D}$ at $2 \mathrm{keV}$. These erosion measurements are influenced by the strong tendency of the nitride to oxidize.
\end{abstract}

PACS numbers: $28.52 . \mathrm{Fa}, 79.20 . \mathrm{Rf}, 82.65 .+\mathrm{r}, 82.80 . \mathrm{Pv}, 82.80 . \mathrm{Yc}$ 
Properties of nitrogen-implanted beryllium and its interaction with energetic deuterium3

\section{Introduction}

Beryllium is planned as a plasma-facing material for the international nuclear fusion experiment ITER [1]. Most of the inner wall of the plasma vessel of this facility will be covered by metallic Be [2]. In the nuclear phase of the experiment the plasma will consist mainly of deuterium and tritium. The Be surface is thus subjected to intense fluxes of these hydrogen isotopes escaping from the magnetically confined plasma. Simultaneous to erosion, hydrogen is implanted and retained in the plasma-facing material. The radioactive isotope tritium poses a safety issue: An in-vessel tritium inventory of $700 \mathrm{~g}$ has been defined as the maximum acceptable level for ITER. Therefore, the fraction of hydrogen atoms retained upon implantation into Be as well as the temperature dependence of the release is of great concern and has been the subject of numerous investigations $[3,4]$.

Seeding of impurities to the plasma has been used for various purposes in many tokamak experiments, among others in TEXTOR [5], ASDEX Upgrade [6] and JET [7, 8]. In ASDEX Upgrade it became a necessity for high power discharges after installation of the full metal wall. The elimination of carbon as an effective divertor and edge plasma radiator made radiative cooling by impurity seeding mandatory in order to reduce the power flux onto the divertor and limiter tiles. Puffing of nitrogen gas through nozzles in the divertor roof baffle reduces the divertor temperature and power flux as well as the ELM size. In addition, in ASDEX Upgrade also the energy confinement was improved [6]. The need for extrinsic radiating species is expected also for JET after installation of the ITER-like wall in $2011[9,10]$.

When nitrogen is introduced into a fusion plasma device, it will partly be transported into the main chamber and implanted or codeposited onto the main wall. Due to the kinetic energy of the particles from the plasma, the formation of surface 
Properties of nitrogen-implanted beryllium and its interaction with energetic deuterium4 compounds between the wall materials and nitrogen (so-called 'mixed materials') is expected even for low surface temperatures at which solid state chemical reactions are not observed [11]. These compound surface layers will influence the physical and chemical properties of the first wall materials significantly. Issues of concern are the alteration of melting points and sputtering yields, chemical erosion by formation of volatile species, formation of insulating layers that might induce arcing, alteration of the retention behavior for hydrogen isotopes, storage and release of large amounts of nitrogen leading to problems in density control, etc. Therefore, the formation and stability range of $\mathrm{N}$-containing compounds is of significant importance to the operation of a fusion device when $\mathrm{N}_{2}$ is used as a seeding gas. Concerns about the use of nitrogen with a tungsten first wall have been addressed in dedicated laboratory experiments [12]. Similar concerns arise for the use of nitrogen with a Be first wall in the main chamber.

For the application of $\mathrm{N}_{2}$ seeding in Be-clad fusion devices, the parameters for compound formation triggered by kinetic nitrogen particles are of importance. Furthermore, the influence of D implantation on compound formation and dissociation, as well as the compound influence on the D inventory are important. In this work the formation of mixed $\mathrm{Be}_{x} \mathrm{~N}_{y}$ layers by kinetic (keV range) nitrogen is investigated and their behavior upon annealing as well as upon D irradiation is studied. The exposure of Be to a N-containing plasma is simulated by controlled implantation of $\mathrm{N}$ ions into polycrystalline Be at room temperature (RT, approx. $300 \mathrm{~K})$. It is shown that beryllium nitride layers are formed. These layers are stable up to annealing temperatures of $1000 \mathrm{~K}$ and no decomposition or diffusion of $\mathrm{N}$ into the Be bulk is observed. The presence of nitrogen changes the release behavior of $\mathrm{D}$, both after RT implantation and after annealing, while the retained fraction of the implanted D is not significantly altered at high D fluences. To our knowledge no such experiments have hitherto been reported in 
Properties of nitrogen-implanted beryllium and its interaction with energetic deuterium5 the literature.

After a description of experimental details in section 2 the subsequent sections deal with the following topics:

- Formation of a chemical compound upon implantation of $\mathrm{N}$ into polycrystalline Be, as characterized by X-ray photoelectron spectroscopy (XPS)

- Thickness and stoichiometry of the mixed $\mathrm{Be}_{x} \mathrm{~N}_{y}$ layers, as deduced from XPS as well as from Rutherford backscattering spectrometry (RBS)

- Behaviour of the nitrogen-rich layers upon annealing to $1000 \mathrm{~K}$

- D retention in the nitrogen-rich layers studied by nuclear reaction analysis (NRA)

- Release temperatures for D observed during temperature-programmed desorption (TPD)

- Chemical shifts in the XPS spectra upon D implantation and possible formation of beryllium amide

- Erosion of the surface compound layers by $2 \mathrm{keV} \mathrm{D}$

- Oxidation of the nitride

Properties of beryllium nitride

At room temperature a stable beryllium nitride phase (cubic $\alpha-\mathrm{Be}_{3} \mathrm{~N}_{2}$ ) is described in the binary bulk phase diagrams [13]. At normal pressure this compound undergoes a phase transition into the hexagonal modification $\beta-\mathrm{Be}_{3} \mathrm{~N}_{2}$ around 1700 to $1800 \mathrm{~K}$. The standard Gibbs free energy $\Delta G_{f}^{0}$ of formation of $\alpha-\mathrm{Be}_{3} \mathrm{~N}_{2}$ is $5.52 \mathrm{eV}$ [14]. This value is very close to $\Delta G_{f}^{0}$ for beryllium oxide $(6.00 \mathrm{eV})$, which readily forms upon exposure of metallic Be to molecular or atomic oxygen [15].

Formation of beryllium nitride after exposure of Be to air is not observed. This is attributed to the very high activation barrier of approx. $1.6 \mathrm{eV}$ for the rate limiting 
Properties of nitrogen-implanted beryllium and its interaction with energetic deuterium6 process in nitride formation on Be [16] as well as to the energetically slightly favored oxide that is readily formed as a thin layer and prevents nitride formation. It has been shown that a thick oxide layer effectively suppresses the nitride formation on Be. However, beryllium nitride is formed upon heating Be in an $\mathrm{N}_{2}$ atmosphere [16].

Soto et al. [17] have grown beryllium nitride thin films by laser ablation of Be in an $\mathrm{N}_{2}$ atmosphere. They reported a maximum $\mathrm{N}$ concentration in the ablated layers corresponding to the $\mathrm{Be}_{3} \mathrm{~N}_{2}$ stoichiometry. The Be 1 s photoelectron binding energy in the nitride deposited at room temperature is $114.0 \mathrm{eV}$ as measured by X-ray photoelectron spectroscopy (XPS). The corresponding binding energy is $114.6 \mathrm{eV}$, when the nitride layers are ablated at $1023 \mathrm{~K}[18,19]$.

Soto et al. also reported a high optical band gap of $3.8 \mathrm{eV}$ of $\mathrm{Be}_{3} \mathrm{~N}_{2}$. In ab initio calculations values above $4 \mathrm{eV}$ were obtained $[20,21,22]$. The stoichiometric nitride can therefore be considered to be electrically insulating at operation temperatures of the first wall in a fusion reactor.

\section{Experimental procedures}

All the experiments presented here are performed at the experimental apparatus ARTOSS at IPP [23]. The general experimental procedures are as described in [24]. We therefore focus only on specific conditions relevant for the described experiments.

\subsection{Sample preparation and surface composition}

The samples are polycrystalline square Be plates with $10 \mathrm{~mm}$ side length and $0.5 \mathrm{~mm}$ thickness (MaTecK). They are produced by vacuum hot isostatic pressing of Be powder and subsequent hot rolling. Polishing with diamond pads and diamond spray results in specular surfaces with no visible scrub marks and a roughness amplitude $R_{a}$ below 
Properties of nitrogen-implanted beryllium and its interaction with energetic deuterium7 $10 \mathrm{~nm}$. The bulk purity of these samples is better than 99.0 at.\%, with oxygen as the main impurity (less than 0.8 at.\% BeO). After introduction into the vacuum vessel of the ARTOSS apparatus numerous cycles of sputtering with $3 \mathrm{keV}$ argon and subsequent annealing to temperatures above $1000 \mathrm{~K}$ are applied in order to clean the sample surface. XPS analysis shows that the amount of surface oxygen after such a treatment is below a monolayer coverage or even below the detection limit of XPS, except when noted. On annealed Be surfaces a silicon signal corresponding to approximately one monolayer can be detected with XPS. The Si probably originates from the polishing process, segregates on the surface during annealing, and is sputtered off during $\mathrm{N}$ or $\mathrm{D}$ irradiation.

\subsection{Nitrogen implantation}

Mixed $\mathrm{Be}_{x} \mathrm{~N}_{y}$ layers are produced by implantation of the Be surface with $\mathrm{N}$ ions from an electron impact ion source (SPECS IQE 12/38) without mass separation. The acceleration voltage is either $3 \mathrm{kV}$ or $5 \mathrm{kV}$. To estimate the depth range of the implanted $\mathrm{N}$ the energy per $\mathrm{N}$ is calculated by dividing the acceleration voltage by a factor 2 . This assessment relies on the assumption that the accelerated particles are singly charged $\mathrm{N}_{2}^{+}$molecules. The assumption is justified by the very strong triple bond of the $\mathrm{N}_{2}$

molecule. In fact also mass spectrometry of $\mathrm{N}_{2}$ yields $\mathrm{N}_{2}^{+}$as the dominantly detected species [25]. The assumption of $\mathrm{N}_{2}^{+}$ions impinging on the surface is further supported by the reasonable agreement of the measured and calculated depth profiles (see section 4). The same assumption is also adopted to determine the $\mathrm{N}$ fluence from the accumulated charge.

\subsection{Deuterium implantation}

Deuterium implantation is performed at room temperature up to various fluences by means of a mass-separated beam of $\mathrm{D}_{3}^{+}$ions. The acceleration voltage is $1.2 \mathrm{kV}$ or 
Properties of nitrogen-implanted beryllium and its interaction with energetic deuterium8

$1.8 \mathrm{kV}$ which - upon dissociation of the molecules at the sample surface - yields implantation energies per atom of $400 \mathrm{eV}$ and $600 \mathrm{eV}$, respectively. The implantation spot is optimized with respect to previous investigations: By means of an ion optical system the D beam is focussed to obtain a full-width-at-half-maximum intensity of approx. $1 \mathrm{~mm}$. This leads to local $\mathrm{D}$ ion fluxes in the center of the beam of up to $1 \times 10^{15} \mathrm{D} \mathrm{cm}^{-2} \mathrm{~s}^{-1}$ (for $600 \mathrm{eV}$ D), as measured with a Faraday cup with an entrance aperture of $0.5 \mathrm{~mm}$ in diameter. A well-defined, homogeneous implantation area with sharp borders is achieved by a motorized sample movement relative to the fixed ion beam. The insert in figure 4 shows an ellipsometry map of the implantation spot after bombardment of an amorphous hydrocarbon layer on top of a silicon substrate by $2 \mathrm{keV}$ $\mathrm{D}$ with a fluence of $7.8 \times 10^{18} \mathrm{~cm}^{-2}$. The changes in shade in this map are induced by the D bombardment, but cannot be directly converted into a depth scale. However, the map gives a quantitative picture of the lateral dimensions of the implantation spot. The homogeneously implanted area is surrounded by a region of less than $1 \mathrm{~mm}$ in width implanted at a lower fluence. The fluences given in the figures 4 and 5 refer to the accumulated number of $\mathrm{D}$ atoms divided by the area of the nominally implanted rectangle.

\subsection{Elemental and chemical analysis}

RBS with ${ }^{4} \mathrm{He}$ in IBM geometry is employed to determine the absolute amounts and the depth distributions of implanted N. For depth profile determination the backscattered particles are recorded at $105^{\circ}$ scattering angle. According to calculations with RESOLNRA $[26,27]$ optimal depth resolution is obtained at a primary energy of the ${ }^{4} \mathrm{He}$ atoms of $800 \mathrm{keV}$. To further increase the depth resolution, the surface normal of the sample is tilted by $7.5^{\circ}$ with respect to the incoming beam, resulting in an angle of $7.5^{\circ}$ between the sample surface plane and the detector. Such shallow exit angles 
Properties of nitrogen-implanted beryllium and its interaction with energetic deuterium9 require a thorough alignment of the sample in the scattering geometry. Since surface roughness has a strong influence on the $\mathrm{N}$ depth profiles deduced from measurements in this geometry, it can only be applied for well-polished samples. Nevertheless, only this additional tilting enables to resolve $\mathrm{N}$ depth profiles for the ion energies used in the keV range. Since any surface roughness results in an apparent $\mathrm{N}$ depth larger than the actual one, the depths assessed in these measurements can be taken as upper limits (see also section 4). For the determination of the partial sputter yield in section 6 the total $\mathrm{N}$ areal densities are extracted from the signals at $165^{\circ}$ scattering angle. The amount of $\mathrm{D}$ retained after implantation is determined by NRA with $650 \mathrm{keV}{ }^{3} \mathrm{He}$. The protons from the reaction $\mathrm{d}\left({ }^{3} \mathrm{He}, \mathrm{p}\right) \alpha$ are detected at $135^{\circ}$ scattering angle.

XPS spectra are recorded in situ before and after each experimental step (N implantation, annealing, D implantation, ion beam analysis). A non-monochromatic $\mathrm{Mg} \mathrm{K} \alpha$ source is used in combination with a hemispherical electron energy analyzer (PHI 10-360). The employed pass energies are $117.4 \mathrm{eV}$ for survey scans and $24.5 \mathrm{eV}$ for high resolution spectra of the $\mathrm{Be} 1 s$, the $\mathrm{N} 1 s$ and the $\mathrm{O} 1 s$ regions. The reference binding energy of the $\mathrm{Au} 4 f_{7 / 2}$ electrons lies at $84.0 \mathrm{eV}$ and additional $\mathrm{Cu}$ and $\mathrm{Ag}$ photoelectron lines are used to adjust the linearity of the energy scale. The reproducibility of the photoelectron binding energies throughout this work is $\pm 0.1 \mathrm{eV}$.

\subsection{Temperature-programmed desorption}

A linear temperature ramp of $0.7 \mathrm{~K} \mathrm{~s}^{-1}$ is used for all TPD spectra. The sample is positioned in line-of-sight of the quadrupole mass spectrometer (QMS). The ramping starts at room temperature and stops at 1000 K. A PID controller (Schlichting HS 770/ HS 170) is employed which allows for linear ramps with deviations of a few percent from the desired heating rate over the temperature range from 400 to $1000 \mathrm{~K}$. The $\mathrm{D}_{2}^{+}$signal $(m / q=4)$ is monitored as well as numerous other mass-to-charge ratios corresponding 
Properties of nitrogen-implanted beryllium and its interaction with energetic deuterium10 to potentially desorbing species.

\section{Beryllium nitride formation upon nitrogen implantation and annealing}

Figure 1 shows XPS spectra of the Be $1 s$ region. A spectrum from unimplanted, annealed Be (with approximately one monolayer of surface oxygen as estimated from the survey spectrum) is plotted together with two spectra recorded after implantation of Be with two different fluences of $\mathrm{N}$ at an acceleration voltage of $3 \mathrm{kV}$. After implantation of $3 \times 10^{16} \mathrm{~cm}^{-2}$ a new peak appears in addition to the one for metallic Be. This peak is separated from the metallic Be signal by $+1.5 \mathrm{eV}$ towards a higher binding energy. This $\mathrm{Be}_{\text {nit }}$ peak is attributed to the formation of beryllium nitride. It is rather broad compared to the spectrometer resolution, which is typical for materials in a disordered state with varying next neighbor atom distances and crystallographic orientations. Fitting of the spectrum with two signals at 111.9 and $113.4 \mathrm{eV}$ results in approximately equal integral intensities of the two peaks after implantation to this fluence. After implantation with a fluence of $1.8 \times 10^{18} \mathrm{~cm}^{-2}$ the nitride peak dominates and the metallic peak is only visible as a small shoulder, corresponding to approx. $7 \%$ of the total signal intensity in the Be $1 s$ region. Further implantation does not change the observed shifts and intensities. This indicates saturation with $\mathrm{N}$ within the information depth range of XPS.

After implantation of $\mathrm{N}$ at $5 \mathrm{kV}$ to high fluences the shoulder from metallic $\mathrm{Be}$ is further attenuated to approximately $4 \%$ (spectrum a in the Be $1 s$ panel of figure 2). Almost all of the Be within the information depth of XPS is in the nitride state. An increase in implantation energy corresponds to an increase in implantation depth, leading to a wider zone saturated in nitrogen. The attenuation of the metallic shoulder is consistent with a longer path for photoelectrons from the metallic substrate through 
Properties of nitrogen-implanted beryllium and its interaction with energetic deuterium11

the nitride layer. It is therefore concluded that after implantation to fluences above saturation the measured intensity at the binding energy corresponding to $1 \mathrm{~s}$ electrons in metallic Be originates from the metallic substrate underneath a layer of $\mathrm{Be}_{x} \mathrm{~N}_{y}$. This conclusion is further supported by XPS spectra with the sample tilted by $60^{\circ}$ with respect to the analyzer. Such a tilting lowers the effective information depth of XPS. Accordingly, the metallic contribution to the Be $1 s$ signal is further reduced in these spectra.

Implantation of fluences above $1.8 \times 10^{18} \mathrm{~cm}^{-2}$ does not further increase the amount of retained $\mathrm{N}$. This is shown in the insert in figure 1 which demonstrates a saturation of the integrated intensity in the $\mathrm{N} 1 s$ binding energy region with increasing $\mathrm{N}$ fluence. Since in XPS measurements the metallic Be substrate still contributes to the signal, the saturation of the surface layer in nitrogen is within the XPS information depth, i.e. within a few nm at the applied X-ray energy. This saturation is corroborated by RBS measurements of the $\mathrm{N}$ amount for selected implantation fluences.

Due to the implantation with energetic $\mathrm{N}$ ions and the associated collision cascades the compound formed is presumably disordered. After heating the N-implanted Be to above $1000 \mathrm{~K}$ the nitride part of the Be $1 s$, as well as the N $1 s$ XPS peaks (both recorded after cooling down to room temperature) are reduced in peak width and shifted towards higher binding energies by +0.7 and $+0.8 \mathrm{eV}$, respectively (figure 2, spectra a and c). Assuming that the annealing treatment enables an ordering process, the narrower XPS peaks can be attributed to such an energetically more favorable atomic structure (see also section 4). Upon reimplantation of the annealed layer with $\mathrm{N}$ the XPS peaks shift back to their positions and widths before annealing.

Within the reproducibility of these measurements $( \pm 0.1 \mathrm{eV})$ the binding energy of the nitride peak in the Be $1 s$ region after annealing corresponds to the value of $114.0 \mathrm{eV}$ 
Properties of nitrogen-implanted beryllium and its interaction with energetic deuterium 12

reported in [17] for beryllium nitride films produced by laser ablation. Although not explicitly stated in [17] we assume that for those measurements the laser ablation was performed at room temperature. When the layers are produced at $1023 \mathrm{~K}$ the Be $1 s$ binding energy is reported to be $114.6 \mathrm{eV}[19,18]$.

After annealing, the metallic signal in the Be $1 s$ region becomes apparent as a separate peak rather than a shoulder. This is partly just due to the fact that the nitride peak shifts further away from the binding energy of the $1 s$ electrons in the metallic substrate. But there is also a net increase in the intensity of the metallic part of the signal from approximately $4 \%$ after implantation with $\mathrm{N}$ at $5 \mathrm{kV}$ to approx. $15 \%$ after the heat treatment. The integrated N $1 s$ signal is reduced by approx. $10 \%$ after the heating. One possible mechanism leading to a larger substrate signal after annealing is the thinning of the nitride layer due to desorption of a small part of the implanted $\mathrm{N}$. Another mechanism is the agglomeration of the nitride during annealing. This can lead to attenuation of nitride photoelectrons from island clusters or even to an uncovering of the Be substrate directly. Further investigations are necessary in order to clarify whether agglomeration or desorption occur during annealing, nevertheless this is only a minor effect.

\section{Nitrogen depth distribution}

Under the assumption of a homogeneous nitride layer on top of a metallic Be substrate the stoichiometry in the nitride layer can be calculated from the areas of the $\mathrm{N} 1 s$ and the nitride part $\mathrm{Be}_{n i t}$ of the $\mathrm{Be} 1 s$ region, weighted with the respective elemental sensitivity factors. For calculating the area of $\mathrm{Be}_{n i t}$ the $\mathrm{Be} 1 s$ region is fitted [28] with two peaks, one around $111.8 \mathrm{eV}$ binding energy for the metallic part and a second one at a higher binding energy for the nitride part. Taking the empirical sensitivity factors 
from [29] ( $S_{B e}=0.074$ and $S_{N}=0.477$ for Be and N, respectively) yields an N/Be ratio of approximately 0.68. The theoretical value for stoichiometric $\mathrm{Be}_{3} \mathrm{~N}_{2}$ is 0.67 . After annealing the experimental N/Be ratio decreases slightly to approximately 0.64.

The influence of the specific inelastic mean free paths (IMFP) of photoelectrons in the beryllium nitride layer on XPS sensitivity factors is neglected in this estimation. For corrections based on existing models $[30,31]$ the mass density of the implanted mixed layer is required. A calculation taking into account the IMFPs according to Gries with the assumption that the mass density in the layer is equal to the one of stoichiometric $\mathrm{Be}_{3} \mathrm{~N}_{2}$ reduces the $\mathrm{N} / \mathrm{Be}$ ratio by $10 \%$. Even though the real mass density of the layer is not known and the precondition of a homogeneous nitride layer can be put into question, we estimate the possible systematic error in the calculation of stoichiometries from the XPS measurements to be in the order of these $10 \%$.

An RBS spectrum after implantation of $\mathrm{N}$ up to saturation and subsequent heating to $1000 \mathrm{~K}$ is shown in figure $3 \mathrm{a}$. The Be edge is clearly visible as well as a peaked $\mathrm{N}$ signal indicating a very shallow $\mathrm{N}$ depth distribution. For the modelling of the RBS spectra with SIMNRA $[27,32,33]$ the best achievable depth resolution in the applied geometry (see section 2) is first calculated using the program RESOLNRA. It amounts to $6 \times 10^{16}$ atoms $\mathrm{cm}^{-2}$. This is taken as the minimum thickness of the layers allowed during manual adaptation of the simulated sample to the experimental spectrum. The elemental depth profile shown in figure $3 \mathrm{~b}$ is the result of this adaptation. It features a $\mathrm{N} / \mathrm{Be}$ ratio at the surface of 0.48 , which is somewhat below the value of 0.67 for stoichiometric $\mathrm{Be}_{3} \mathrm{~N}_{2}$. This tendency is in agreement with the stoichiometry calculated by XPS when the corrections to the IMFPs according to Gries are taken into account. After implantation with $\mathrm{N}$ to saturation the $\mathrm{N}$ concentration profile is expected to peak at the surface (with a possible plateau). A possible influence of surface roughness or 
Properties of nitrogen-implanted beryllium and its interaction with energetic deuterium14

inhomogeneous layer thickness together with the limited depth resolution of the RBS measurements can consequently only lower the observed $\mathrm{N}$ concentration at the very surface. Therefore, the value of 0.48 can be considered a lower limit for the $\mathrm{N} / \mathrm{Be}$ ratio at the surface.

The depth-integrated areal density of $\mathrm{N}$ is approx. $4 \times 10^{16} \mathrm{~cm}^{-2}$. The $\mathrm{N}$ concentration depth profile falls below 1 at. $\%$ within roughly $1 \times 10^{17} \mathrm{~cm}^{-2}$. In order to convert this into a length scale we assume the density of the mixed layer to be equal to the density of $\mathrm{Be}_{3} \mathrm{~N}_{2}$, namely $1.5 \times 10^{23}$ atoms $\mathrm{cm}^{-3}$ [34]. This yields a layer thickness of $9 \mathrm{~nm}$ within which the nitrogen concentration exceeds 1 at.\%. As discussed in section 2, the depths assessed in this way can be considered to be upper limits.

In order to estimate the amount of $\mathrm{N}$ that according to these RBS measurements might have diffused into the bulk (either already upon implantation or upon subsequent annealing), a thorough analysis of the spectra is conducted in the following. The signal is not entirely zero to the right of the $\mathrm{N}$ surface peak. This stems from heavier impurities which are present in the bulk of the sample to less than 1 at. $\%$ according to the specifications. The major impurity is $\mathrm{O}$ with a concentration of less than 0.4 at.\%. The main heavier impurity is iron (less than 0.08 at.\%). These impurities are included in the simulation. They cause a constant low-level signal in all lower channels on top of which the dominant $\mathrm{N}$ and Be signals appear. The RBS signal between the $\mathrm{N}$ peak and the Be edge is slightly higher than the signal that originates from impurities with mass 16 or higher. This could be attributed to boron or carbon impurities in the bulk or to $\mathrm{N}$ which diffused into the bulk during annealing. Other possible origins are multiple scattering effects and surface roughness. A maximum $\mathrm{N}$ concentration of 0.5 at. $\%$ in depths larger than $15 \mathrm{~nm}$ is compatible with the low level signal to the right of the Be edge. However, the actual cause for the increased signal is most probably surface 
roughness, which is expected to play a role in these measurements due to the very shallow detection angle (see section 2). Therefore, it is concluded from this analysis that no $\mathrm{N}$ bulk diffusion occurs during annealing of the $\mathrm{N}$-implanted layer.

The experimental results are compared to dynamic simulations with SDTrim.SP $[35,36]$ for irradiation of Be with $\mathrm{N}$ at $2.5 \mathrm{keV}$ (corresponding to singly charged $\mathrm{N}_{2}^{+}$ molecules accelerated by $5 \mathrm{kV}$ ). In dynamic equilibrium (which in these simulations is reached at fluences above $8 \times 10^{17} \mathrm{~N} \mathrm{~cm}^{-2}$ ) a pure nitrogen layer is established at the very surface. The obvious reason for this is that SDTrim.SP only treats kinematics and does not account for other reaction paths such as the $\mathrm{N}_{a d s}+\mathrm{N}_{a d s} \rightarrow \mathrm{N}_{2}$ recombination and desorption of $\mathrm{N}_{2}$ from the surface. In order to obtain a surface layer of stoichiometric $\mathrm{Be}_{3} \mathrm{~N}_{2}$ in dynamic equilibrium (which then is reached already above $2 \times 10^{17} \mathrm{~N} \mathrm{~cm}^{-2}$ ) the maximum $\mathrm{N}$ fraction in the calculations is restricted to 0.4 (see figure $3 \mathrm{~b}$ ). With the partial atomic volume of the $\mathrm{N}$ atoms in this layer adapted to yield the correct density for $\mathrm{Be}_{3} \mathrm{~N}_{2}$ the resulting thickness of the layer is $10 \mathrm{~nm}$. This depth range is in agreement with the depth profiles calculated from the RBS measurements.

\section{Deuterium retention in and desorption from beryllium nitride}

D implantation into the thin nitride layers must be performed at adequately small ion energies. The chosen implantation energies of $400 \mathrm{eV}$ for the small fluences and $600 \mathrm{eV}$ for the higher fluences are a compromise between this criterion and a reasonable beam current of the order of $100 \mathrm{nA}$. According to static simulations with SDTrim.SP the maxima of the implantation profiles for $\mathrm{D}$ implanted into $\mathrm{Be}_{3} \mathrm{~N}_{2}$ at 400 and $600 \mathrm{eV}$ lie at $6.5 \mathrm{~nm}$ and $11 \mathrm{~nm}$, respectively.

From previous experiments on clean Be surfaces [24, 37] the release behavior of D implanted at $1 \mathrm{keV}$ per atom is known to change considerably above a threshold fluence 
Properties of nitrogen-implanted beryllium and its interaction with energetic deuterium16 of $1.2 \times 10^{17} \mathrm{~cm}^{-2}$. In the following $\mathrm{D}$ retention in and release from nitride layers is described after implantation of D to fluences far below, as well as above this threshold fluence.

Figure 4 shows D desorption spectra after implantation at $400 \mathrm{eV}$ per atom with fluences of approximately $5.5 \times 10^{15} \mathrm{~cm}^{-2}$, applying temperature ramps of $0.7 \mathrm{~K} \mathrm{~s}^{-1}$. The oxygen contamination of the surface, as determined by XPS, is well below 1 monolayer of $\mathrm{BeO}$ during all steps of these experiments. In the cases of $\mathrm{D}$ implantation into a nitride layer ( $\mathrm{b}$ and $\mathrm{c}$ ) this layer is established by implantation of $\mathrm{N}$ at $5 \mathrm{kV}$ acceleration voltage. The thermally treated layer $\mathrm{c}$ is implanted with $\mathrm{N}$ and subsequently annealed at $1000 \mathrm{~K}$ before implantation of D.

The larger peaks at desorption temperatures above $600 \mathrm{~K}$ in the spectra a and $\mathrm{c}$ are attributed to D released from ion-induced traps [24] created upon implantation of low D fluences into Be and into the annealed mixed layer, respectively. The release flux from the annealed mixed layer peaks around $630 \mathrm{~K}$, i.e. at slightly lower temperatures compared to clean Be, where the desorption maximum lies at $675 \mathrm{~K}$. Furthermore, a small D amount still desorbs from the $\mathrm{N}$ implanted surface at temperatures above $750 \mathrm{~K}$ at which no desorption is observed from clean Be. The increase in all three signals above $900 \mathrm{~K}$ is due to the increasing sublimation of Be: Twofold ionization of Be leads to a $m / q=4.5$, i.e. close to the one for singly charged $\mathrm{D}_{2}$. This produces a signal at $m / q=4$ due to the limited resolution of the measurement.

In cases a and c a first low-temperature release is observed around 480 to $490 \mathrm{~K}$. This peak is only observed upon desorption from polycrystals, and is only prominent for very small implantation fluences. At higher fluences (still below saturation), it only plays a minor role compared to the main desorption peak at higher temperatures. It could originate from deuterium being released from grain boundaries or impurities, which are 
both absent in single crystals. In the unannealed case b most of the $\mathrm{D}$ is released in a broader peak around $550 \mathrm{~K}$. At temperatures above $700 \mathrm{~K}$ the spectrum b follows the behavior of the annealed nitride, case c.

The retained fractions of $\mathrm{D}$ are $0.62,0.44$ and 0.47 for cases $\mathrm{a}, \mathrm{b}$ and $\mathrm{c}$, respectively. The uncertainty in these numbers is mainly due to the uncertainty in the calibration of the QMS signal. It is conservatively estimated to $10 \%$. Apparently the presence of $\mathrm{N}$ slightly reduces the retention of $\mathrm{D}$ at low fluences. This can be attributed to an increased reflection by the heavier $\mathrm{N}$ atoms in comparison to Be. In experiments on single crystalline Be implanted with $\mathrm{D}$ at $1 \mathrm{keV}$ the retained fraction was almost 0.8 at low fluences [24]. The lower retained fractions in the experiments presented here can be attributed to the different trap evolution upon $\mathrm{D}$ implantation between single and polycrystalline Be [39]. Also the improved beam scanning technique described in section 2 and the therefore more homogeneous fluence over the implanted area compared to the previous experiments can influence the measured retained fractions.

Figure 5 shows the $\mathrm{D}$ desorption behavior after implantation at $600 \mathrm{eV}$ per atom with fluences above the saturation threshold. The D fluences were 2.8, 2.1 and $1.9 \times 10^{17} \mathrm{~cm}^{-2}$ for the spectra a, b and c, respectively. In case a the 'clean' Be carries a surface oxygen contamination slightly higher than in all other experiments shown: The XPS intensities correspond to a few monolayers of BeO.

The spectra b and c for N-implanted Be feature a large low-temperature desorption peak, as does the spectrum a for clean Be. For the cases a and c the peak maximum lies around $440 \mathrm{~K}$, while in the unannealed case b it is shifted to $470 \mathrm{~K}$. The spectra $\mathrm{b}$ and c show an increased desorption at intermediate temperatures (between 480 and $680 \mathrm{~K}$ ), while they lack the pronounced peak at the high temperature end of the spectrum that is observed above $700 \mathrm{~K}$ in the spectrum a from clean Be. 
Properties of nitrogen-implanted beryllium and its interaction with energetic deuterium18

At 600 eV implantation energy, according to static SDTrim.SP calculations a major part of the $\mathrm{D}$ atoms is implanted into the bulk Be below the thin nitride layer. The activation barrier for release of these atoms from their initial trapping site is therefore that for clean beryllium. The observed desorption temperature is then additionally influenced by the diffusion of D from the initial trap to the surface, as observed in [38] and [39]. A reduced diffusivity for $\mathrm{D}$ through disordered $\mathrm{Be}_{3} \mathrm{~N}_{2}$ qualitatively explains the shift of the dominant low-temperature desorption peak to higher temperatures in the unannealed case b. Following the same reasoning, the similar peak temperatures of the low-temperature desorption stage in the cases a and c indicate a similar diffusion coefficient for D through the annealed (and D implanted) nitride layer as through clean (and D implanted) Be.

The retained fractions for the three cases a, b and $\mathrm{c}$ are $0.31,0.45$ and 0.41 , respectively. The reduced fraction in case a can be attributed to the higher implanted fluence increasing the effect of saturation. Therefore, within the error margin of the experiment, at the applied implantation energy the retention of $\mathrm{D}$ at high fluences is not affected by the presence of nitrogen.

In addition to the $\mathrm{D}_{2}^{+}$signal $(m / q=4)$ the mass-to-charge ratios corresponding to numerous $\mathrm{D}$ and $\mathrm{N}$ containing species that might desorb upon temperature ramping are monitored during the TPD experiments. Many of them feature a steady increase with temperature that cannot be assigned to desorption from the implanted surface, but must rather be attributed to the increasing background pressure, as well as to N-containing molecules originating from adsorbates on the sample holder. The only desorption spectrum with a characteristic peak (as expected for decomposition of a limited amount of a substance) is that of $m / q=20$, corresponding to deuterated ammonia $\left(\mathrm{ND}_{3}\right)$. This spectrum (as recorded after $\mathrm{D}$ implantation into an annealed 
Properties of nitrogen-implanted beryllium and its interaction with energetic deuterium19 nitride layer) is plotted in figure 5 , together with the signals for $\mathrm{D}_{2}^{+}$after high fluence D implantation. A broad peak around $620 \mathrm{~K}$ is observed. The onset temperature for this desorption peak is $550 \mathrm{~K}$. This corresponds to the temperature at which according to [40] beryllium amide $\left(\mathrm{Be}\left(\mathrm{NH}_{2}\right)_{2}\right)$ decomposes into the imide $(\mathrm{BeNH})$ and the nitride $\left(\mathrm{Be}_{3} \mathrm{~N}_{2}\right)$ while releasing ammonia: $4 \mathrm{Be}\left(\mathrm{NH}_{2}\right)_{2} \rightarrow \mathrm{BeNH}+\mathrm{Be}_{3} \mathrm{~N}_{2}+5 \mathrm{NH}_{3}$.

The desorption of $\mathrm{ND}_{3}$ is only observed in our experiments after implantation of high D fluences $\left(>10^{17}\right)$ and the intensity of the corresponding QMS signal is almost two orders of magnitude smaller than the $\mathrm{D}_{2}^{+}$signal. A corresponding signal at the mass to charge ratio of $m / q=18\left(\mathrm{ND}_{2}^{+}\right)$with $80 \%$ of the intensity of the signal at $m / q=20$ would support the interpretation of desorbing deuterated ammonia. However, this verification is made impossible by fact that the signal at $m / q=18$ is dominated by $\mathrm{H}_{2} \mathrm{O}^{+}$and is more than an order of magnitude higher than at $m / q=20$ throughout the spectrum. In conclusion, even though there is an indication for beryllium amide formation, the trapping of $\mathrm{D}$ in form of $\mathrm{Be}\left(\mathrm{ND}_{2}\right)_{2}$ plays a minor role.

XPS core level shifts also suggest the formation of ternary Be-N-D compounds: After implantation of the nitride layers by D the XPS peaks of both Be $1 s$ and N $1 s$ shift towards higher binding energies (see figure 2). Upon D implantation directly after $\mathrm{N}$ implantation without prior annealing (spectra a vs. b) both the nitride peak in the Be $1 s$ signal and the $\mathrm{N} 1 s$ signal shift to higher binding energies by $+0.9 \mathrm{eV}$. Implantation into the annealed nitride layer (spectra c vs d) results in shifts by $+0.3 \mathrm{eV}$ in addition to the shifts already induced by the annealing, which are +0.7 and $+0.8 \mathrm{eV}$, for $\mathrm{Be} 1 s$ and $\mathrm{N} 1 s$, respectively (see section 3). There are two reasons for excluding that the shifts observed upon D bombardment are an effect of disorder introduced in the layer by the energetic ions: First, the $\mathrm{N}$ implanted, unannealed sample is already disordered. Further ion bombardment (with a lighter species) is not expected to introduce further 
Properties of nitrogen-implanted beryllium and its interaction with energetic deuterium20

disorder. Second, as discussed in section 3, the ordering process assumed during annealing shifts the peaks towards higher binding energies, while introduction of disorder by re-implantation with $\mathrm{N}$ causes shifts back to lower binding energies. Consequently, the shifts to higher binding energies upon D implantation are attributed to the formation of ternary chemical compounds.

\section{Erosion and oxidation beryllium nitride}

In order to measure the erosion of the nitride layer by impinging energetic $\mathrm{D}$ ions, a series of RBS measurements with increasing D fluence is performed. The starting point for the erosion series is a saturated nitride layer (implanted with $1.7 \times 10^{18} \mathrm{~N} \mathrm{~cm}^{-2}$ without subsequent annealing). D irradiation is performed at $2 \mathrm{keV}$ per atom and the $\mathrm{N}$ areal density is measured by RBS with $800 \mathrm{keV}{ }^{4} \mathrm{He}$ at $165^{\circ}$ scattering angle after each fluence step. Figure 6 shows the results of these measurements as a function of the D fluence. From a linear fit to these data a partial sputtering yield of $0.013 \mathrm{~N} / \mathrm{D}$ is obtained. For comparison, the partial sputter yield of oxygen in BeO upon irradiation with $\mathrm{D}$ ions at $2 \mathrm{keV}$ has been determined to $0.015 \mathrm{O} / \mathrm{D}$ by weight loss measurements $[41]$.

The erosion series is performed over several days. XPS measurements show that the amount of oxygen at the surface grows with time in between the erosion steps while the background pressure is less than $1.5 \times 10^{-10}$ mbar. The developed oxygen coverage is sputtered off in the subsequent D fluence step. This effectively lowers the apparent partial sputter yield deduced from figure 6 which is why the value of $0.013 \mathrm{~N} / \mathrm{D}$ is considered a lower estimate. 


\section{Summary}

Clean polycrystalline $\mathrm{Be}$ is implanted with $\mathrm{N}$ ions at $\mathrm{keV}$ energies. This causes the formation of a nitride compound in the implanted surface layer. Around a fluence of $2 \times 10^{18} \mathrm{~cm}^{-2}$ the $\mathrm{N}$ content saturates within the implantation range of less than $10 \mathrm{~nm}$, leading to a maximum retained areal density of approx. $4 \times 10^{16} \mathrm{~N} \mathrm{~cm}^{-2}$. Annealing of the compound formed upon implantation induces an ordering process which is reflected in higher XPS binding energies and reduced peak widths in the Be $1 s$ and $\mathrm{N} 1 s$ binding energy regions. The N/Be ratio within the first few $\mathrm{nm}$ is determined with XPS as well as RBS and is consistent with the formation of stoichiometric $\mathrm{Be}_{3} \mathrm{~N}_{2}$. No decomposition of the nitride or diffusion of $\mathrm{N}$ into the Be bulk is observed upon heating of the layer to $1000 \mathrm{~K}$.

The dominant desorbing species in TPD runs performed after implantation of D into the nitride layer at 400 and $600 \mathrm{eV}$ is $\mathrm{D}_{2}$, while the contribution of other $\mathrm{D}$ containing compounds is negligible. At a D fluence of $5.5 \times 10^{15} \mathrm{~cm}^{-2}$ the release of $\mathrm{D}$ from the disordered nitride occurs at notably different temperatures compared to clean polycrystalline Be, while after implantation into the annealed nitride the release behavior shows similar features as from clean Be. From the desorption spectra recorded after implantation to fluences around $2 \times 10^{17} \mathrm{~cm}^{-2}$ an influence of the nitride layer on the $\mathrm{D}$ diffusion is deduced. The fraction of the $\mathrm{D}$ fluence that is retained after implantation into the nitride layer and beyond is similar to the one for clean Be.

The partial sputter yield for $\mathrm{N}$ by $2 \mathrm{keV} \mathrm{D}$ is determined to $0.013 \mathrm{~N} / \mathrm{D}$ as a lower limit. This is comparable to the yield for $\mathrm{O}$ on $\mathrm{BeO}$. 
Properties of nitrogen-implanted beryllium and its interaction with energetic deuterium22

\section{Conclusions regarding the use of nitrogen seeding with a beryllium first wall}

The nitride compound formed upon implantation of $\mathrm{N}$ ions into Be is thermally stable and does not decompose when heated up to $1000 \mathrm{~K}$. The melting temperature of bulk $\mathrm{Be}_{3} \mathrm{~N}_{2}$ is known from the literature to be higher than the one for metallic $\mathrm{Be}[13]$. Melting point reduction due to compound formation upon $\mathrm{N}$ ion implantation into Be is therefore not an issue.

The absence of diffusion of $\mathrm{N}$ (even at elevated temperatures) leads to the saturation of the Be surface with $\mathrm{N}$ within the implantation zone. The thickness of this zone is less than $10 \mathrm{~nm}$ for implantation of $\mathrm{N}$ at $2.5 \mathrm{keV}$ and will be even less for the lower implantation energies expected at the main walls of ITER. In a fusion reactor the nitride layer will be subjected to erosion by impinging $\mathrm{D}$ ions, which will lead to further thinning. The actual thickness of the N-rich layer in dynamic equilibrium therefore also depends on the ratio of $\mathrm{D}$ to $\mathrm{N}$ influx on the Be tiles. The determined partial $\mathrm{N}$ sputter yield by $\mathrm{D}$ indicates that a pure $\mathrm{D}$ fluence of $3 \times 10^{18} \mathrm{~cm}^{-2}$ suffices to remove the saturated nitride layer formed by $5 \mathrm{keV}$ implantation of $\mathrm{N}$. With estimated $\mathrm{D}$ fluences

onto the Be main wall in ITER on the order of $4 \times 10^{19} \mathrm{~cm}^{-2}$ per discharge [4] the nitride layer will therefore be removed from plasma wetted Be areas by sputtering within one ITER discharge.

The risk of increased arcing due to the insulating character of thin nitride layers can be compared to the natural self-passivating oxide layer that is formed at room temperature on Be in the presence of oxygen or water molecules. In fact such an oxide layer will cover the Be first wall at the onset of plasma operation. This layer has a thickness of a few nm and $\mathrm{BeO}$ is a better insulator with a band gap of $10.6 \mathrm{eV}$ [42] compared to $3.8 \mathrm{eV}$ for $\mathrm{Be}_{3} \mathrm{~N}_{2}$. However, no quantitative evaluation of the insulating 
action of thin layers is attempted here.

No drastic influence of the $\mathrm{N}$ irradiation on $\mathrm{D}$ retention in Be surfaces is observed in the measurements presented in this work. From thermal desorption spectra recorded after implantation of Be with $\mathrm{N}$ to saturation and subsequently with high fluences of $\mathrm{D}$ an influence of the N-rich layer on $\mathrm{D}$ diffusion can be inferred. However, the nitride layers do not act as a barrier for out-diffusion of $\mathrm{D}$. The influence of $\mathrm{N}$ on the $\mathrm{D}$ retention in Be co-deposits (which play a major role in the total D retention in fusion devices with Be wall elements) is not addressed and further work is necessary.

One of the advantages of using Be in a fusion device is its high affinity to oxygen, leading to a reduced impurity content in the plasma. It is observed in this work that also the saturated nitride layer oxidizes quickly even in high vacuum. These measurements indicate that the oxidation rate of the nitride is similar to the one of clean Be and that therefore the desired gettering property of Be is preserved. 
Properties of nitrogen-implanted beryllium and its interaction with energetic deuterium 24

\section{References}

[1] ITER Physics Basis Editors, ITER Physics Expert Group Chairs, Co-Chairs, ITER Joint Central Team, and Physics Integration Unit, Nucl. Fusion 39 (1999) 2137.

[2] M. Shimada, D.J. Campbell, V. Mukhovatov, M. Fujiwara, N. Kirneva, K. Lackner, M. Nagami, V.D. Pustovitov, N. Uckan, J. Wesley, N. Asakura, A.E. Costley, A.J.H. Donné, E.J. Doyle, A. Fasoli, C. Gormezano, Y. Gribov, O. Gruber, T.C. Hender, W. Houlberg, S. Ide, Y. Kamada, A. Leonard, B. Lipschultz, A. Loarte, K. Miyamoto, V. Mukhovatov, T.H. Osborne, A. Polevoi, and A.C.C. Sips, Nucl. Fusion 47 (2007) S1.

[3] R. A. Anderl, R. A. Causey, J. W. Davis, R. P. Doerner, G. Federici, A. A. Haasz, G. R. Longhurst, W. R. Wampler, and K. L. Wilson, J. Nucl. Mater. 273 (1999) 1.

[4] J. Roth, E. Tsitrone, A. Loarte, Th. Loarer, G. Counsell, R. Neu, V. Philipps, S. Brezinsek, M. Lehnen, P. Coad, Ch. Grisolia, K. Schmid, K. Krieger, A. Kallenbach, B. Lipschultz, R. Doerner, R. Causey, V. Alimov, W. Shu, O. Ogorodnikova, A. Kirschner, G. Federici, and A. Kukushkin, J. Nucl. Mater. 390-391 (2009) 1.

[5] J. Rapp, M. Z. Tokar, L. Könen, H. R. Koslowski, G. Bertschinger, M. Brix, H. Claassen, R. Jaspers, A. Krämer-Flecken, K.Ohya, V. Philipps, A. Pospieszczyk, U. Samm, T. Tanabe, G. Telesca, B. Unterberg, and G. Van Oost, Plasma Phys. Control. Fusion 39 (1997) 1615.

[6] A. Kallenbach, R. Dux, M. Mayer, R. Neu, T. Pütterich, V. Bobkov, J.C. Fuchs, T. Eich, L. Giannone, O. Gruber, A. Herrmann, L.D. Horton, C.F. Maggi, H. Meister, H.W. Müller, V. Rohde, A. Sips, A. Stäbler, J. Stober, and ASDEX Upgrade Team, Nucl. Fusion 49 (2009) 045007.

[7] J. Rapp, M.R. de Baar, W. Fundamenski, M. Brix, R. Felton, C. Giroud, A. Huber, S. Jachmich, E. Joffrin, I. Nunes, G.J. van Rooij, M. Stamp, G. Telesca, and R. Zagorski, J. Nucl. Mater. 390-391 (2009) 238.

[8] J. Rapp, Y. Corre, Y. Andrew, M.R. de Baar, M. Beurskens, S. Brezinsek, M. Brix, S. Devaux, T. Eich, R. Felton, W. Fundamenski, C. Giroud, D. Howell, A. Huber, S. Jachmich, E. Joffrin, A. Korotkov, G.F. Matthews, D.C. McDonald, A. Meigs, P. Monier-Garbet, P. Morgan, I. Nunes, G.J. van Rooij, O. Sauter, M.F. Stamp, G. Telesca, P.C. de Vries, R. Zagorski, and JET-EFDA contributors, Nucl. Fusion 49 (2009) 095012.

[9] G. F. Matthews, P. Edwards, T. Hirai, M. Kear, A. Lioure, P. Lomas, A. Loving, C. Lungu, H. Maier, P. Mertens, D. Neilson, R. Neu, J. Pamela, V. Philipps, G. Piazza, V. Riccardo, 
Properties of nitrogen-implanted beryllium and its interaction with energetic deuterium25

M. Rubel, C. Ruset, E. Villedieu, and M. Way on behalf of the ITER-like Wall Project Team, Phys. Scr. (2007) 137.

[10] V. Philipps, Ph. Mertens, G.F. Matthews, and H. Maier, Fusion Eng. Des. In Press, doi:10.1016/j.fusengdes.2010.04.048 (2010) .

[11] Ch. Linsmeier, M. Reinelt, and K. Schmid, submitted to J. Nucl. Mater. (2010).

[12] K. Schmid, A. Manhard, Ch. Linsmeier, A. Wiltner, T. Schwarz-Selinger, W. Jacob, and S. Mandl, Nucl. Fusion 50 (2010) 025006.

[13] H. Okamoto and L. Tanner, Phase Diagrams of Binary Beryllium Alloys, Monograph Series on Alloy Phase Diagrams (ASM International, Materials Park, Ohio, 1987), 123-127.

[14] I. Barin, Thermochemical Data of Pure Substances, volume 1 \& 2 (VCH, Weinheim, 1995), 3rd edition.

[15] Ch. Linsmeier and J. Wanner, Surf. Sci. 454-456 (2000) 305.

[16] E. A. Gulbransen and K. F. Andrew, J. Electrochem. Soc. 97 (1950) 383.

[17] G. Soto, J. A. Díaz, R. Machorro, A. Reyes-Serrato, and W. de la Cruz, Mater. Lett. 52 (2002) 29.

[18] G. Soto, W. de la Cruz, and M. H. Farías, J. Electron. Spectrosc. 135 (2004) 27.

[19] W. De La Cruz Hernandez, J. D. Hernandez, and G. Soto, Surf. Sci. Spectra 10 (2003) 14.

[20] Ma. G. M. Armenta, A. Reyes-Serrato, and M. A. Borja, Phys. Rev. B 62 (2000) 4890.

[21] Ma. G. M. Armanta and A. Reyes-Serrato, Comp. Mater. Sci. 21 (2001) 95.

[22] A. Mokhtari and H. Akbarzadeh, Physica B 337 (2003) 122.

[23] Ch. Linsmeier, P. Goldstraß, and K. U. Klages, Phys. Scr. T94 (2001) 28.

[24] M. Reinelt, A. Allouche, M. Oberkofler, and Ch. Linsmeier, New J. Phys. 11 (2009) 043023.

[25] S.E. Stein director, NIST Chemistry WebBook, NIST Standard Reference Database Number 69, Eds. P.J. Linstrom and W.G. Mallard, chapter "Mass Spectra" (http://webbook.nist.gov, retrieved July 16, 2010).

[26] M. Mayer, Nucl. Instrum. Meth. B 266 (2008) 1852.

[27] M. Mayer, http://www.rzg.mpg.de/ mam/ .

[28] MultiPak, Physical Electronics Corp., Ver. 6-8 (1994-2006).

[29] J. F. Moulder, W. F. Stickle, P. E. Sobol, and K. D. Bomben, Handbook of X-ray Photoelectron Spectroscopy (Physical Electronics Inc., Minnesota, 1995).

[30] W. H. Gries, Surf. Interface Anal. 24 (1996) 38. 
[31] S. Tanuma, C. J. Powell, and D. R. Penn, Surf. Interface Anal. 21 (1994) 165.

[32] M. Mayer, SIMNRA User's Guide, Report IPP 9/113 (1997).

[33] M. Mayer, AIP Conf. Proc. 475 (1999) 541.

[34] P. Eckerlin and A. Rabenau, Z. Anorg. Allg. Chem. 304 (1960) 218.

[35] W. Eckstein, Computer Simulation of Ion-Solid Interactions, volume 10 (Springer, Berlin, Series in Materials Science, 1991).

[36] W. Eckstein, R. Dohmen, A. Mutzke, and R. Schneider, SDTRIMSP: A Monte Carlo Code for Calculating Collision Phenomena in Randomized Targets, Report IPP 12/3 (2007).

[37] M. Oberkofler, M. Reinelt, A. Allouche, S. Lindig, and Ch. Linsmeier, Phys. Scr. T138 (2009) 014036.

[38] M. Oberkofler, M. Reinelt, S. Lindig, and Ch. Linsmeier, Nucl. Instrum. Meth. B 267 (2009) 718.

[39] A. Allouche, M. Oberkofler, M. Reinelt, and Ch. Linsmeier, J. Phys. Chem. C 114 (2010) 3588.

[40] H. Jacobs and R. Juza, Z. Anorg. Allg. Chem. 370 (1969) 248.

[41] J. Roth, J. Bohdansky, R.S. Blewer, W. Ottenberger, and J. Borders, J. Nucl. Mater. 85-86 (1979) 1077.

[42] D.M. Roessler, W.C. Walker, and E. Loh, J. Phys. Chem. Solids 30 (1969) 157. 
Figure 1. XPS spectra of the Be $1 s$ region after implantation of $\mathrm{N}$ up to different fluences into Be. The insert shows the integrated N $1 s$ intensity which saturates with increasing $\mathrm{N}$ fluence.

Figure 2. XPS spectra of the Be $1 s$ and $\mathrm{N} 1 s$ regions after various experimental steps.

Figure 3. (a) Experimental and simulated RBS spectrum of the nitride layer on Be after annealing. (b) Depth profiles used for the SIMNRA simulation (full lines, sum of $\mathrm{O}$ and $\mathrm{Fe}$ impurities at 1 at.\% throughout the whole depth) as well as the depth profiles calculated by dynamic SDTrim.SP (dotted lines).

Figure 4. TPD spectra at $m / q=4$ (corresponding to $\mathrm{D}_{2}^{+}$) recorded after implantation at $400 \mathrm{eV} / \mathrm{D}$ to $5.5 \times 10^{15} \mathrm{~cm}^{-2}$. The insert shows an ellipsometry map of the implantation spot.

Figure 5. Curves $\mathrm{a}, \mathrm{b}$ and $\mathrm{c}$ are TPD spectra at $m / q=4$ (corresponding to $\mathrm{D}_{2}^{+}$) recorded after implantation at $600 \mathrm{eV} / \mathrm{D}$ to $2.8,2.1$ and $1.9 \times 10^{17} \mathrm{~cm}^{-2}$, respectively. The curve with the bad signal to noise ratio shows the QMS signal at $m / q=20$, corresponding to $\mathrm{ND}_{3}^{+}$.

Figure 6. Integrated $\mathrm{N}$ areal density as measured by RBS after various fluence steps with $\mathrm{D}$ at $2 \mathrm{keV} /$ atom. The linear fit to the data points results in a sputtering yield $Y$ of 0.013 . 
Properties of nitrogen-implanted beryllium and its interaction with energetic deuterium28

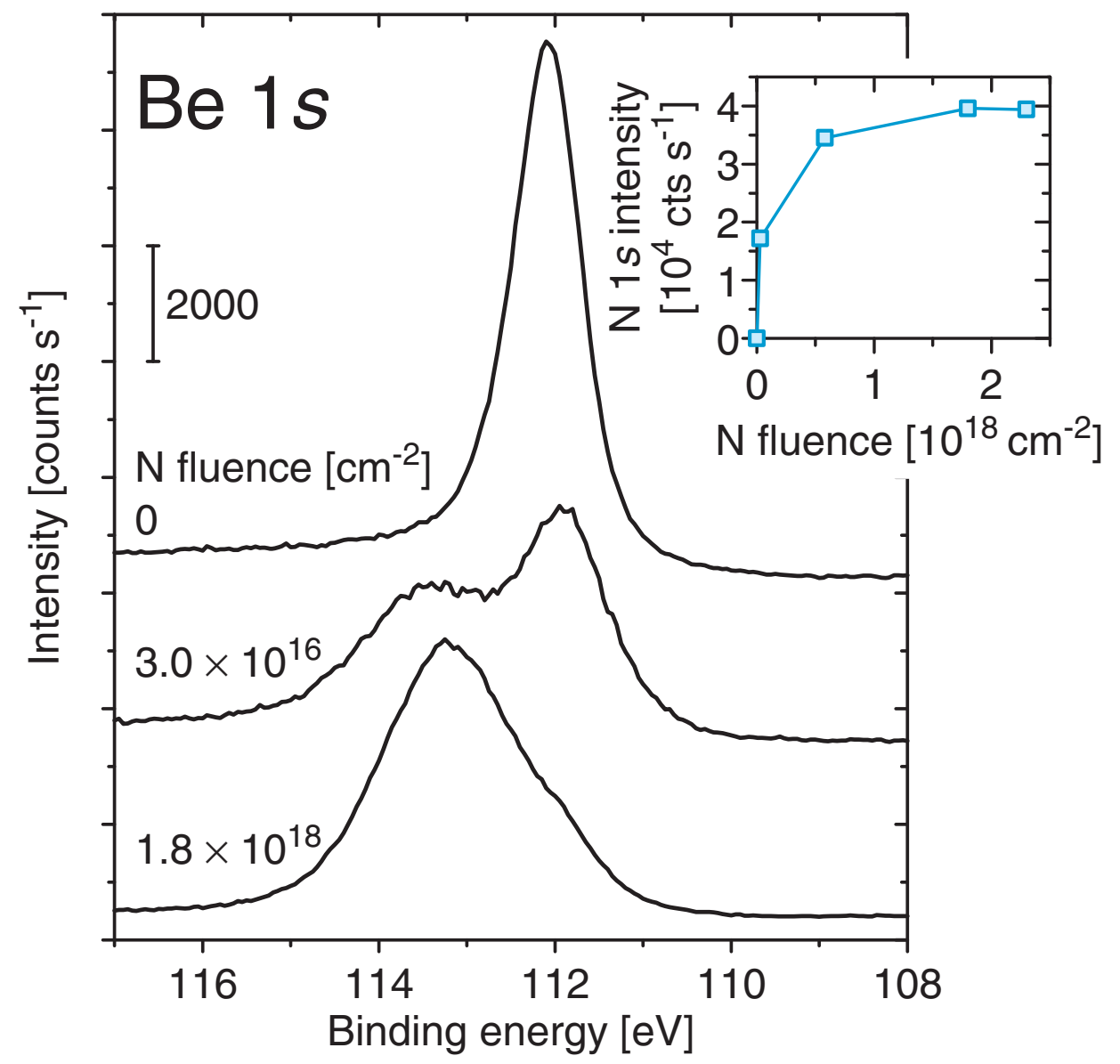

Fig. 1 


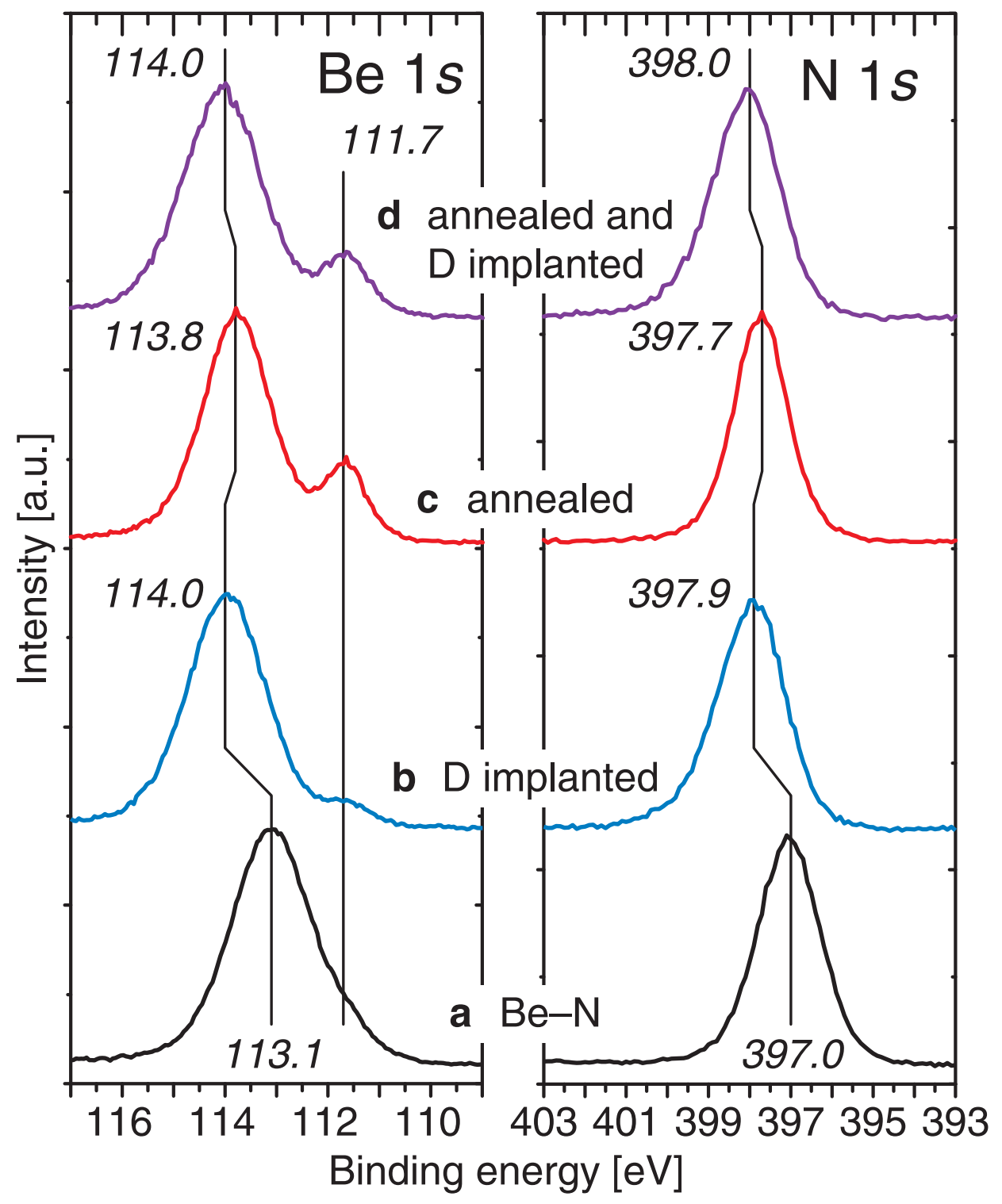

Fig. 2 

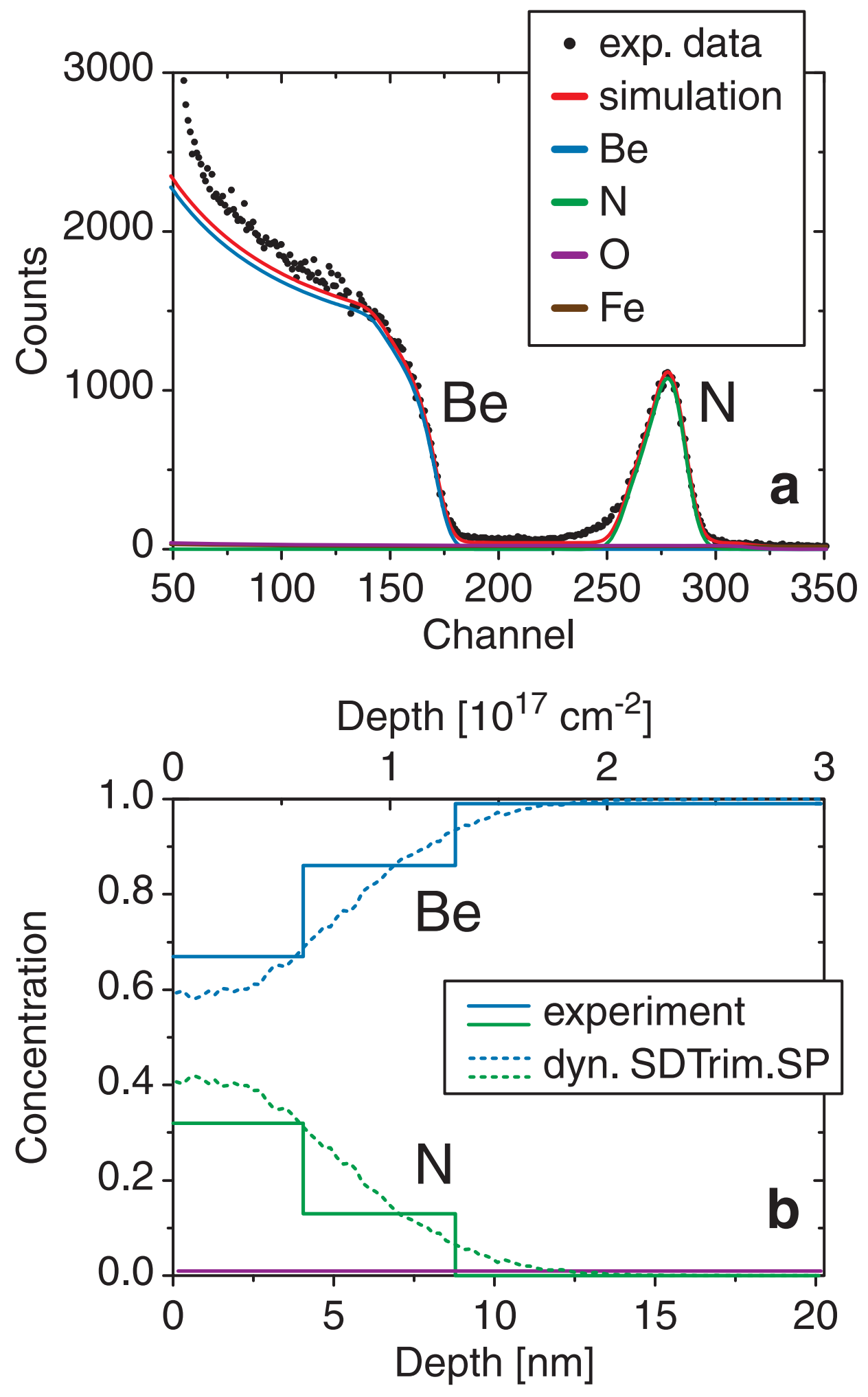

Fig. 3 
Properties of nitrogen-implanted beryllium and its interaction with energetic deuterium31

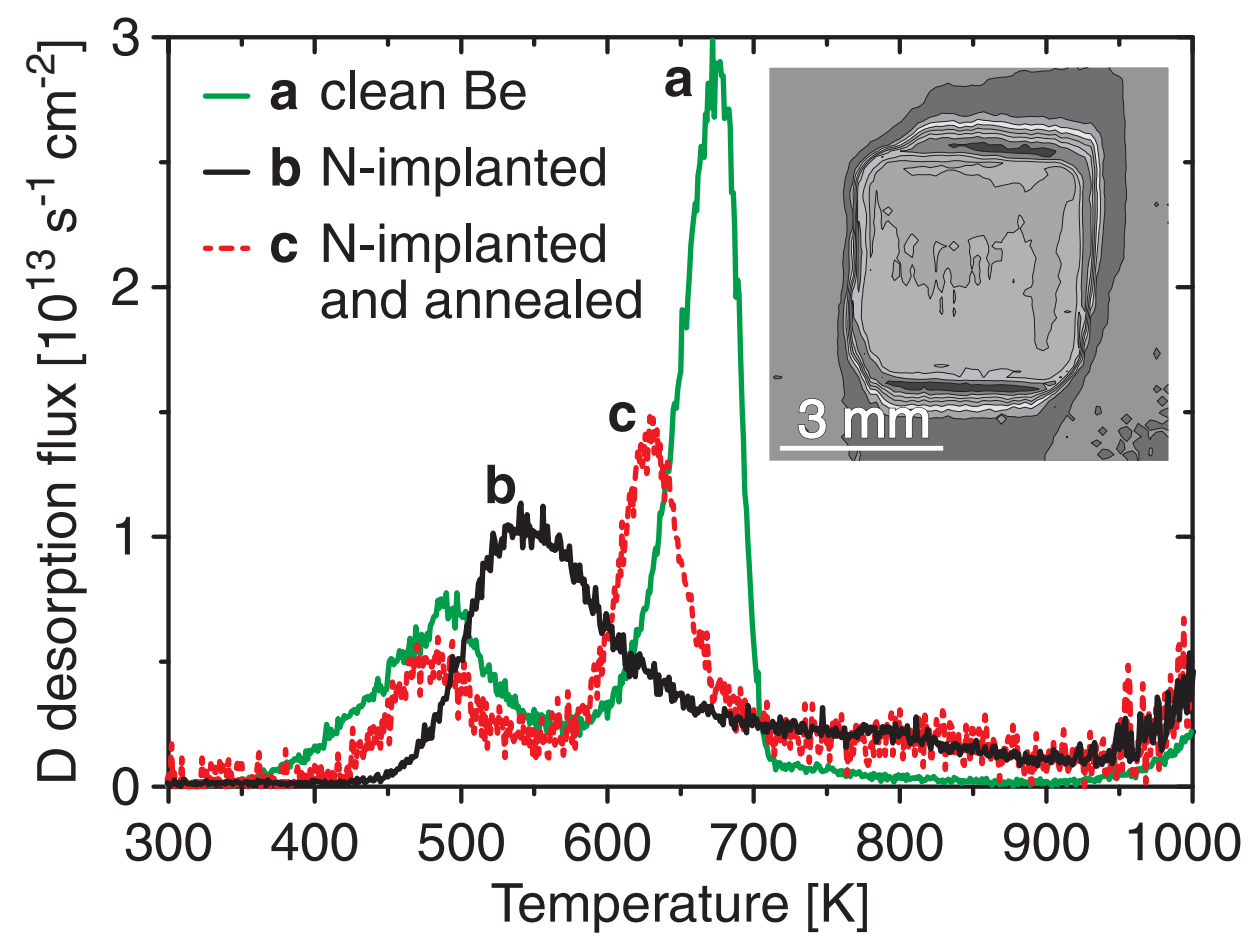

Fig. 4 
Properties of nitrogen-implanted beryllium and its interaction with energetic deuterium32

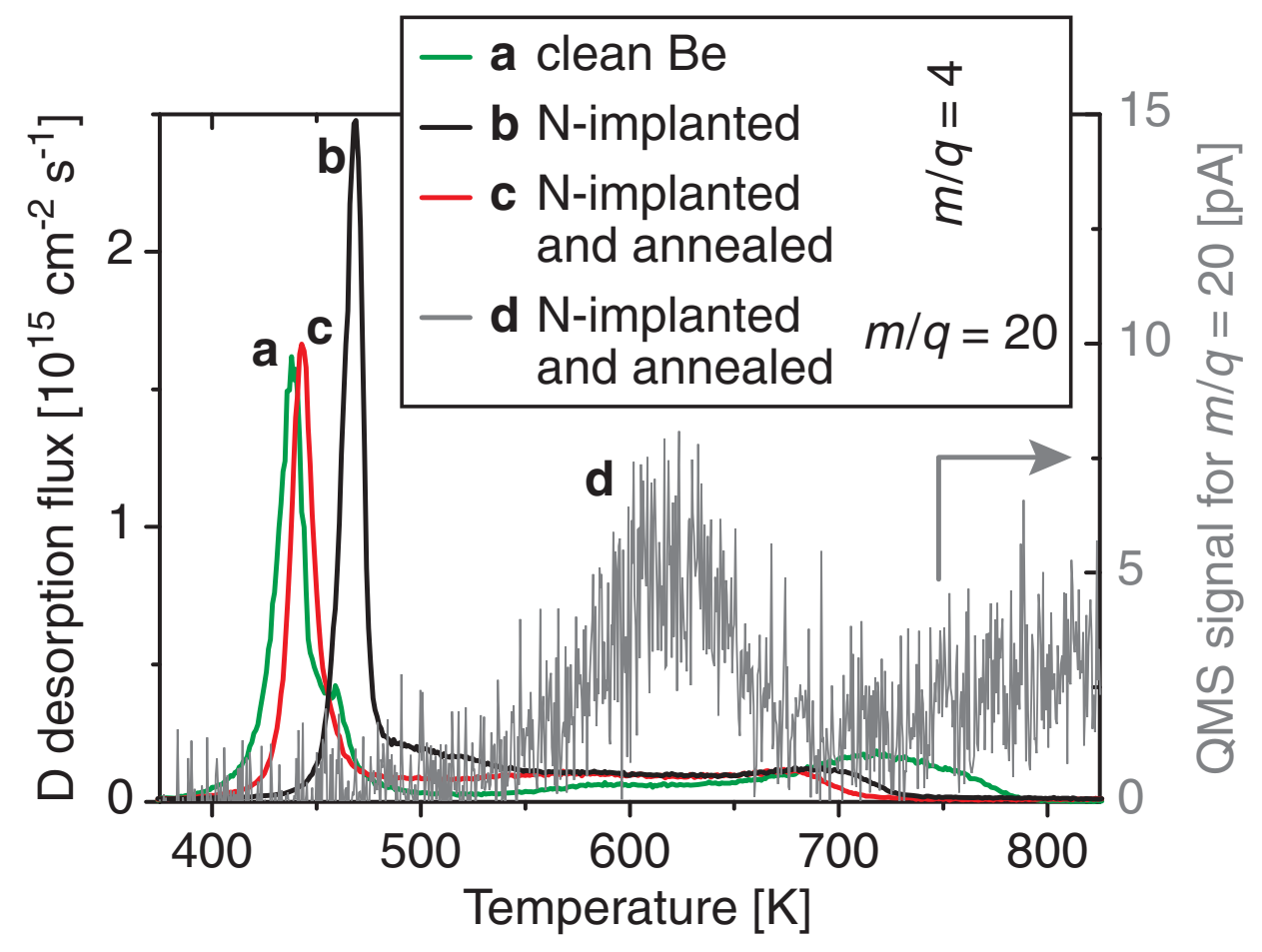

Fig. 5 
Properties of nitrogen-implanted beryllium and its interaction with energetic deuterium33

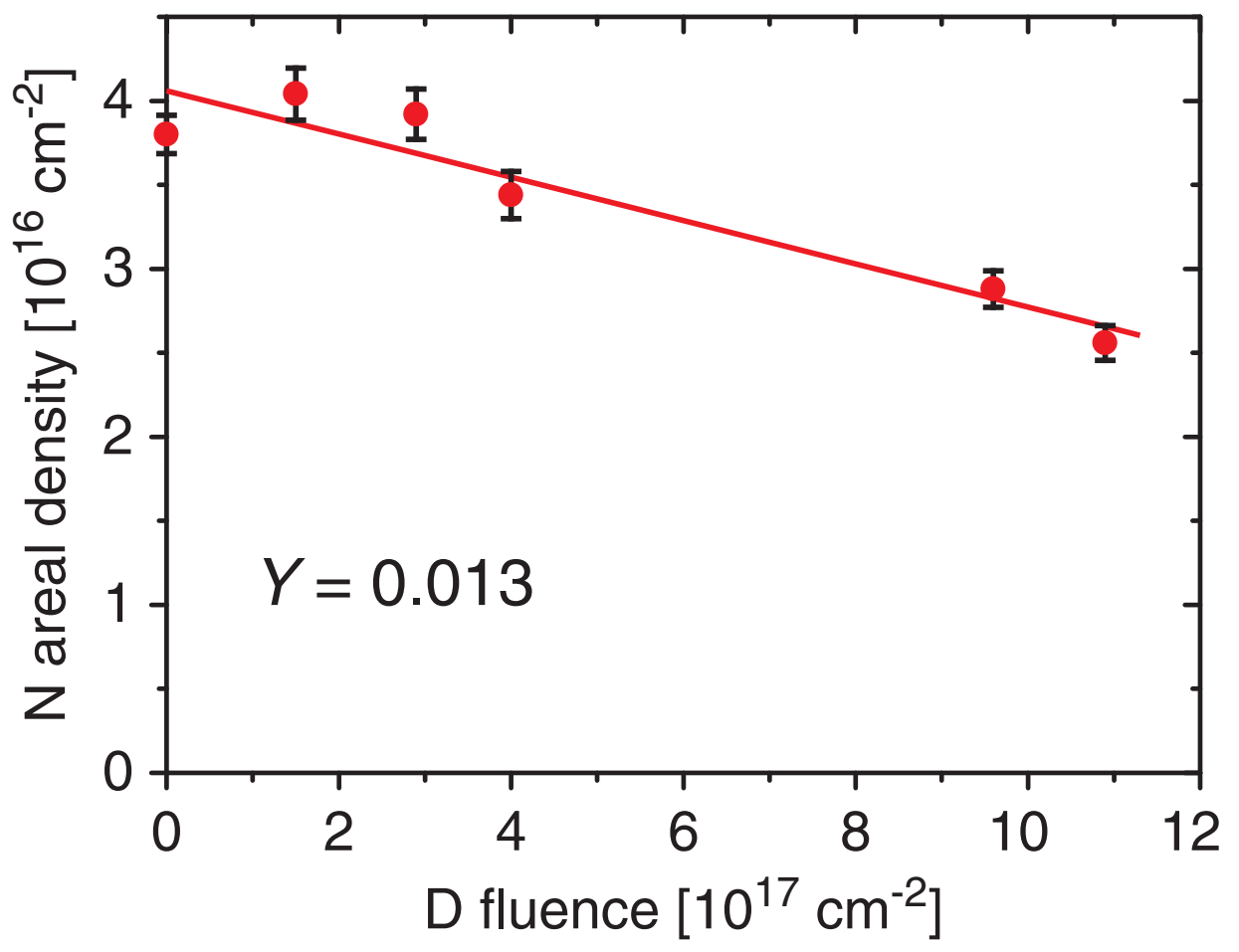

Fig. 6 